\section{CONCEPT AND PRACTICE OF ELECTRONIC PRESCRIPTION}

\section{Jan Bruthans, Jiří Kofránek, Adam Vojtěch}

\begin{abstract}
The simple definition of Electronic prescription (EP) can be met by different approaches as encoding the whole data of a prescription to a QR-code or a memory card. Also, the data can be sent directly to a particular pharmacy. Still, a unified national system with central storage is the only way how to guarantee wide benefits - not only the basic ones but also the advanced such as exploiting the gathered data and using automated clinical decision support. The Czech Republic at present features a widely used national EP system for its development state-of-the art method of process modeling has been used. Most other EU countries are endowed with a similar system, although few exceptions (e.g., Germany with only a pilot phase) exist. Also, the interoperability of EP in the EU is still not widely developed with only four countries with this feature.
\end{abstract}

\section{Keywords}

eHealth, Information System, Electronic prescription, Drug prescription

\section{Introduction}

Electronic prescription (EP, also denoted as ePrescription, eRx, Electronic Prescription System) is usually defined as the Substitution of a paper-based prescription with an electronic data carrier [1]. Typically, the paper-based prescriptions are used in an outpatient setting only, as there is usually a much lower need for such a formalism in an in-patient department. Therefore, under the term EP, we predominantly discuss the Outpatient EP.

Although there is no international standardization of paper-based prescriptions they do not differ significantly in most countries and typically they are recognized abroad with the only concern of who is going to pay for the dispensed medication. Also, quite surprisingly, the general outlay of a paper-based prescription was almost the same more than 120 years ago [2].

EP is no novelty either, as the first pilot of such a system was introduced in Sweden almost 40 years ago. At that time memory card was used as a data carrier and later clinical decision system was added [3]. Significantly later, in 2000, Sweden was also the first to launch a functional nation-covering EP. From 2004 patient was able to choose the pharmacy of his choice [4]. Most European followed the Swedish example and introduced their EP in the last years. Unfortunately, the particular EP systems are not described amply in the literature, sometimes such description is only mentioned incidentally as the article focuses on other aspects. Information has to be gathered from different sources, using and analyzing also laws, news articles, ministry presentations, etc.

Interestingly, there is no international standard of EP which means the particular systems differ significantly as each country has chosen its way of introducing EP. Interoperability between different systems is therefore also a challenge.

This article aims to discuss not only theoretical aspects of EP but also to show different ways of using EP in various countries.

\section{How to fulfill the definition of EP}

As already stated, the definition of EP is very plain as only the data carrier is considered. Let us show different ways how to fulfill this definition:
- The whole data of a prescription might be encoded in a QR-code (a two-dimensional version of a barcode) that is printed on paper and handed to the patient. Needless to say, the paper has still to be physically handed over in the pharmacy, but at least the typical drawbacks of a classical prescription (e.g., illegibility, risk of data alteration, etc.) is diminished. Those kinds of systems are used in South Ireland and Wales - ironically they are not compatible one with the other [5]!

- The data might be loaded in a memory card (a Smart-card is usually mentioned). This approach was used not only initially in Sweden forty years ago but was seriously considered in 2006 as a national EP system in Germany. The primary function of the card was an insurance certificate with a secondary data carrier function. However, for different reasons, the project was not successful and was abandoned in 2010 [6].

- The prescription data might be sent directly to a particular pharmacy. This method is widely used in a system called Surescripts in the USA. Usage of this system is required under the Meaningful Use Program for eHealth introduction and some states in the USA (e.g. New York) made the usage of this system compulsory for physicians [7]. In addition, a Master Patient Index is used to get the information about prescribed drugs in one patient from different physicians when needed.

Although all above-mentioned systems do comply with the basic definition of EP, the first two are unable to deliver the more advanced functions of EP (see next chapter). The Surescripts might be able to do so, but with complications.

Therefore, the best way how to fulfill the definition is a wide unified system with the central storage. That means the physician sends data about the prescribed drugs to this storage. The pharmacist then downloads this data from the storage and medication is dispensed accordingly. The identification of a particular prescription is the main challenge. When a unique identifier of a prescription is used, such an identifier must be handed to the patient which later presents it to the pharmacist. Nonetheless, it is not necessary to print out this identifier as nowadays it can be sent to the patient's mobile phone or his email. If EP can be connected to a national eGovernment register, then there are other ways how to identify the patient (e.g., a national identity card or patient's social security identifier can be used).

To enable wide coverage, the EP system should cover the whole population, which means at least the whole nation. And indeed, most EP systems used in the EU are based on a whole-nation principle. Still, exceptions exist:

- The EP systems in Italy [8] and in Spain [9] are based on regional principles, which means that there are smaller not interconnected systems in every province in each of these states. The reason for this approach might be that the individual provinces are in charge of their healthcare systems.

- In a country with diverse healthcare insurance companies, the EP systems might be operated by such companies. That means that patients in the same region belong to a different EP system according to their affiliation to the insurance company. Due to the dilatory approach of the state authorities when introducing EP this principle is used in contemporary Slovakia. With three insurance companies, there are three different EP systems that every physician and pharmacist have to use concurrently [10].

\section{Benefits of EP}

There is an adage in the army saying that "Generals tend to arm for the previous war". The same issue exists with eHealth when stakeholders tend to see the introduction of electronic means to substitute the "traditional way of doing things" (e.g., writing 
daily notes on a typewriter) by "using new means and doing it same" (e.g., writing daily notes in a plain text in a computer).

This can be also seen in the EP following the EP definition. Thus, the main benefits are identified in the context of the change of the data carrier. Illegibility of the physician's handwriting might be a serious issue. Numerous studies have already proven that using information technologies diminishes errors in this field $[11,12]$. The act of copying data from paper-based prescriptions to the pharmacist's system is not only error-free but can be also time-consuming. Therefore using EP and seamless transfer of data can diminish workload in the pharmacy and speed up the process [13]. Patients have readily identified their time savings as they can obtain a prescription without the need to visit the physician at all [14]. Also, the electronic prescription, contrary to the classical one, cannot be lost.

Although the above-mentioned benefits are readily identified by patients, physicians, and politicians alike, the advanced avails fall into entirely different realms. Firstly, there is the possibility to exploit the gathered prescription data. Fragmentation of health care is nowadays a serious issue and it is quite common that the patient visits various physicians, sometimes even of the same specializations (poetically so-called "doctor shopping" in the literature). With no EP system in place, it is the sole responsibility of the patient to inform his physicians of all medication he/she is taking. But with a functional EP system, this can be achieved independently as every physician can see the whole medication list. Thus, potentially harmful interactions between medications can be prevented $[15,16]$. Another important topic is drug abuse which is not limited to opioids but usually includes also various tranquilizers. Possible misuse of such drugs can be readily identified when there is an EP system present. The term "primary non-compliance" describes the share of prescriptions that are not even taken to the pharmacy - meaning such drugs are certainly not taken by the patient as they were not received by the patient in the first place. This primary non-compliance is assumed between 0.28 percent and a staggering 30 percent [17]. Although no EP system can persuade the patient to visit the pharmacy, at least the prescribing physician can see whether the patient has received the medication.

Secondly, prescription data should be connected to other eHealth systems, such as Electronic Medical Record (e.g., Hospital Information system in one institution) or even Electronic Health Record (EHR), such as a national system that gathers and stores patients' health data, laboratory results, etc. Studies show that connecting EP to other systems significantly increases the safety of health care [18].

And thirdly, after the gathered prescription data can be exploited and EP is interconnected with EHR, Clinical Decision System (CDS) can be introduced. Using automated decision support extensively limits adverse events, improves antibiotics and anticoagulant dosing, and limits polypharmacy, especially in the elderly $[19,20]$.

\section{Development of EP in the Czech Republic}

The Law in the Czech Republic made provision for the EP at the end of 2008. However, the State Institute for Drug Control (SIDC) launched the first version of EP in 2011. For several years the system was not cultivated and its usage among Czech physicians was virtually non-existent [21].

In the meantime, however, legislative steps have already been taken to force the introduction of mandatory usage of EP for physicians and pharmacies alike. After a three-year postponing this obligation (except for specific situations) was introduced for January 2018. Although seen with considerable controversy, this move has undoubtedly "turned the table". The main markers of use (ratio of electronic prescriptions to all prescriptions issued and ratio of physicians using EP to all physicians) have risen from single-digit numbers to an overwhelming majority. Details are set in Table 1.

There was a need to expand the EP by creating the patient drug record informing the prescriber of all the patient's medications. It was not just about making the appropriate software. The key was to develop the relevant legislation that would accurately describe all the required processes for the creation and use of the electronic prescription and the patient drug record.

One of the tools that facilitate interdisciplinary understanding is process modeling using hierarchical state diagrams [22]. In preparing legislation on electronic prescriptions and patient records, a method and system for automated requirements modeling was implemented in Craft.CASE (http://www.craftcase. com). This system is based on software support for the BORM methodology $[23,24]$. Craft.CASE program was used as a kind of imaginary "pencil" with which the process architecture of the electronic prescription system was drawn. The process architecture diagram was then used as a means of communication for interdisciplinary understanding $[25,26]$.

The Parliament of the Czech Republic approved the prepared legislation. In the middle of 2020, the electronic shared drug record of the patient was launched. The patient drug record allows the attending physician, pharmacist, and patient to look at the list of prescribed medicines and thus reveal possible duplications in medications or unwanted interactions.

Process modeling made it possible to quickly prepare a parliamentary amendment to the law, which extends the patient's drug record to the record of all vaccinations and thus creates an electronic vaccination card. In the future, this may include other features, such as a vaccination calendar or an automatic notification, for example, via SMS, about the need to undergo revaccination after a specific time. The Parliament of the Czech Republic approved the amendment, and the SIDC is currently preparing its software implementation.

\section{Current State of EP in EU}

As we have already stated in the Introduction section, the scientific literature lacks sufficient descriptions of EP in various countries. The following information is therefore based on our previous research. Some of the data were obtained by a literature

Table 1 - Czech Electronic Prescription - usage

\begin{tabular}{|c|c|c|c|c|c|c|c|c|}
\hline & 2013 & 2014 & 2015 & 2016 & 2017 & 2018 & 2019 & 2020 \\
\hline Electronic prescriptions / $\Sigma$ prescriptions & $1 \%$ & $2 \%$ & $2 \%$ & $2 \%$ & $7 \%$ & $80 \%$ & $96 \%$ & $98 \%$ \\
\hline Physicians using EP / $\Sigma$ phycisicians & & $2 \%$ & $4 \%$ & $5 \%$ & $35 \%$ & $84 \%$ & $90 \%$ & $90 \%$ \\
\hline Pharmacies using EP / $\Sigma$ pharmacies & $29 \%$ & $37 \%$ & $49 \%$ & $57 \%$ & $94 \%$ & $100 \%$ & $100 \%$ & $100 \%$ \\
\hline
\end{tabular}


review when not only scientific literature but also other means of "grey literature" (e.g. laws, web pages of various institutions, news articles, etc.) were analyzed [27]. Other data was gathered by a survey among European scientists that research EP in their respective countries [28].

There were functional widely used EP systems in 21 of $27 \mathrm{EU}$ countries in 2018. Another two countries had a different system, albeit with some characteristics of EP. One of them was France with a voluntary drug record called Le Dossier Pharmaceutique where all medication dispensed in the last four months is stored. Another is Luxemburg with a national EHR system called Dossier de soins partagé in which currently used medication is recorded by the family physician. Its usage is also voluntary. One country (Poland) had a running pilot study of the EP system and there were no EP systems and no pilot programs of EP system in the last three countries (Bulgaria, Ireland, and Germany). There were also four different and non-compatible EP systems in UK (England, Scotland, North Ireland, and Wales), but as UK has already left the EU, we will not discuss it extensively.

As of 2021, the Polish EP system has been made compulsory, so Poland has joined the rank of EU countries with a functional and widely used EP system [29]. Starting from 1st May 2021, all prescriptions have been made electronic in Bulgaria [30]. Due to the Covid-19 situation, a special email system (under the name National electronic prescription transfer system) has been introduced in Ireland in 2020. Although it falls out of the central storage category, it meets the basic criteria for an EP system, so we may safely count Ireland as a country with one [31]. The first pilot programs of the EP system have recently started in Germany with plans for full usage in 2022 [32]. We have found no information about plans to standardize different systems of France and Luxemburg, so we may conclude they have chosen to remain with their approach.

The first results of European eHealth Digital Service Infrastructure (eHDSI) ePrescription came in 2019 when EP issued in Finland could be dispensed in Croatia and medication issued in the Croatian EP system was obtainable in Estonia. As you see, the eHDSI project works always "one-way" meaning that scenario A (EP prescribed in one state, medication dispensed elsewhere) and scenario B (EP prescribed elsewhere and dispensed in that state) are dealt with separately. The data is always routed through a National Contact Point for eHealth of both the prescribing and dispensing state, so national EP systems have to be connected to these national points only. However, scenarios A and B have to be always tested with every two possible combinations as EP systems do differ in every country. Although former plans were much more ambitious, at present only Portugal has joined the system, so with some exceptions [33], we can say that EPs issued in Croatia, Estonia, Finland, and Portugal can be used in all these states.

As already stated in previous chapters, most countries use one national EP system with central storage, although exceptions as to more independent systems with storage exist (Spain and Italy with regional ones and Slovakia with insurance companies-based ones). Also, the Irish system tends to have more similarity to the American Surescript system than to the national central storage.

Most of the EP systems rely on end-user applications, sometimes web applications are used as a supplemental solution (e.g., for emergency use when the main infrastructure is inoperative). Notable exceptions are Greece, Portugal, and Italy with primary web-based applications. Very common is nowadays also the access to the medication list, so previously prescribed medication can be assessed by the pharmacist and/or physician. Although mandatory usage of the EP system might be seen as controversial, most systems in the EU are obligatory for both physicians and pharmacists. Sometimes this obligation is limited to insurance-covered medication only. Advanced functions of various EP systems exist, most typically there is some kind of automated decision support technology present in the system.

\section{Conclusion}

Although the basic definition of EP is quite simple and there are humble ways how to fulfill it, to achieve significant benefits much more complex solution should be chosen. A national EP system with central storage is the most convenient way to do so. However, the EP system should not be designed as a standalone system. On the contrary, great effort should be devoted to connecting the EP system with other eHealth systems. To do so, not only technical but also law aspects should be addressed.

Most of the EU countries are nowadays equipped with a functional EP system that meets the criteria of the above-mentioned solution. In the last few years, also under some influence of the current Covid-19 situation, there were introduced EP systems in additional EU countries. The last EU country that remains without a functional EP system is Germany, although also the French and Luxembourgian systems cannot be classified as "full" EP systems.

\section{References}

[1.] Black AD, Car J, Pagliari C, Anandan C, Cresswell K, Bokun T, et al. The Impact of eHealth on the Quality and Safety of Health Care: A Systematic Overview. Plos Med 2011;8. https://doi.org/10.1371/journal. pmed.1000387.

[2.] Potter S. Prescription Writing. A Compend of Materia Medica 1902. https://www.henriettes-herb.com/eclectic/potter-comp/prescription. html (accessed September 24, 2019).

[3.] Klein GO. History of Electronic Prescriptions in Sweden: From Time-Sharing Systems via Smartcards to EDI. In: Impagliazzo J, Lundin P, Wangler B, editors. Hist. Nord. Comput. 3, vol. 350, Berlin, Heidelberg: Springer Berlin Heidelberg; 2011, p. 65-73. https://doi. org/10.1007/978-3-642-23315-9 8.

[4.] Deetjen U. European E-Prescriptions: Benefits and Success Factors. Work Pap Ser Cyber Stud Programme 2016:21.

[5.] Health Information and Quality Authority. ePrescribing: An International Review 2018.

[6.] Drews P, Schirmer I. The Failed Implementation of the Electronic Prescription in Germany - A Case Study, Münster: 2015.

[7.] Toohey SL, Andrusaitis J, Boysen-Osborn M, Billimek J, Jen M, Rudkin S. Comparison of primary compliance in electronic versus paper pre scriptions prescribed from the emergency department. Am J Emerg Med 2018;36:1902-4. https://doi.org/10.1016/j.ajem.2018.02.003.

[8.] Valverde JL. The European Electronic Health Record. Critics and future. Pharm Policy Law 2018;19:247-57. https://doi.org/10.3233/ PPL-180461.

[9.] Medinilla Corbellini A, Giest S, Artmann J, Heywood J, Dumortier J. Country Brief: Spain (eHealth Strategies) 2010.

[10.] Ministerstvo zdravotníctva. Erecept - Často kladené otazky 2018. [Ministry of health. E-prescription - Frequently asked questions 2018.]. https://old.ezdravotnictvo.sk/ezdravie/FAQ/ZPR-PZS/Stranky/ erecept.aspx (accessed October 15, 2019).

[11.] Ammenwerth E, Duftschmid G, Gall W, Hackl WO, Hoerbst A, Janzek-Hawlat S, et al. A nationwide computerized patient medication history: Evaluation of the Austrian pilot project "e-Medikation." Int J Med Inf 2014;83:655-69. https://doi.org/10.1016/j.ijmedinf.2014.06.004.

[12.] Moniz TT, Seger AC, Keohane CA, Seger DL, Bates DW, Rothschild $J M$. Addition of electronic prescription transmission to computerized prescriber order entry: Effect on dispensing errors in community pharmacies. Am J Health Syst Pharm 2011;68:158-63. https://doi. org/10.2146/ajhp080298. 
[13.] Timonen J, Kauppinen H, Ahonen R. Impact of electronic prescription on the job descriptions of community pharmacy staff in Finland a survey of pharmacy owners. J Pharm Health Serv Res 2016;7:22531. https://doi.org/10.1111/jphs.12145.

[14.] Klepser D, Lanham A, Cochran G. Electronic prescriptions: opportunities and challenges for the patient and pharmacist. Adv Health Care Technol 2016:1. https://doi.org/10.2147/AHCT.S64477.

[15.] Schedlbauer A, Prasad V, Mulvaney C, Phansalkar S, Stanton W, Bates DW, et al. What Evidence Supports the Use of Computerized Alerts and Prompts to Improve Clinicians' Prescribing Behavior? J Am Med Inform Assoc 2009;16:531-8. https://doi.org/10.1197/jamia.M2910.

[16.] Taylor LK, Kawasumi Y, Bartlett G, Tamblyn R. Inappropriate pre scribing practices: the challenge and opportunity for patient safety. Healthc Q Tor Ont 2005;8 Spec No:81-5.

[17.] Esposito D, Schone E, Williams T, Liu S, CyBulski K, Stapulonis R, et al. Prevalence of Unclaimed Prescriptions at Military Pharmacies. J Manag Care Pharm 2008;14:541-52. https://doi.org/10.18553/ jmcp.2008.14.6.541.

[18.] Kaushal R, Kern LM, Barrón Y, Quaresimo J, Abramson EL. Electronic Prescribing Improves Medication Safety in Community-Based Office Practices. J Gen Intern Med 2010;25:530-6. https://doi.org/10.1007/ s11606-009-1238-8.

[19.] Durieux P, Trinquart L, Colombet I, Niès J, Walton R, Rajeswaran A et al. Computerized advice on drug dosage to improve prescribing practice. In: The Cochrane Collaboration, editor. Cochrane Database Syst. Rev., Chichester, UK: John Wiley \& Sons, Ltd; 2008, p. CD002894. pub2. https://doi.org/10.1002/14651858.CD002894.pub2.

[20.] Clyne B, Bradley MC, Hughes C, Fahey T, Lapane KL. Electronic Prescribing and Other Forms of Technology to Reduce Inappropriate Medication Use and Polypharmacy in Older People: A Review of Current Evidence. Clin Geriatr Med 2012;28:301-22. https://doi. org/10.1016/j.cger.2012.01.009.

[21.] Bruthans J. The past and current state of the Czech outpatient electronic prescription (eRecept). Int J Med Inf 2019;123:49-53. https://doi.org/10.1016/j.ijmedinf.2019.01.003.

[22.] Harel D. Statecharts: a visual formalism for complex systems. Sci Comput Program 1987;8:231-74. https://doi.org/10.1016/01676423(87)90035-9.

[23.] Knott R, Merunka V, Polak J. The BORM Method: A Third Generation Object-Oriented Methodology. In: Liu L, Roussev B, editors. Manag. Object-Oriented Dev. Process, IGI Global; 2006, p. 337-60. https://doi. org/10.4018/978-1-59140-604-4.ch015.

[24.] Knott RP, Merunka V, Polak J. Process modeling for object oriented analysis using BORM Object Behavioral Analysis. Proc. Fourth Int. Conf. Requir. Eng. ICRE 2000 Cat No98TB100219, Schaumburg, IL, USA: IEEE Comput. Soc; 2000, p. 7-16. https://doi.org/10.1109/ ICRE.2000.855566.

[25.] Kofránek J, Berger J, Polák J, Vojtěch A. Modelování eHealth procesů pomocí hierarchických stavových automatů (statecharts) [Modeling of eHealth processes using hierarchical state machines (statecharts)]. Medsoft 2018;30:44-60. https://doi.org/10.35191/medsoft_2018_1_30_44_60.

[26.] Kofránek J, Berger J, Štěpán Petr J, Vrubel F, Vojtěch, Adam. Modelování procesů e-preskripce [Modeling of e-prescription processes]. Medsoft 2019;31:27-32. https://doi.org/10.35191/medsoft $2019 \quad 1 \quad 31 \quad 27 \quad 32$.

[27.] Bruthans J. Elektronická preskripce v České republice a evropském kontextu [The electronic prescription in the Czech Republic and in the European context]. Olomouc: ANAG; 2020.

[28.] Bruthans J. The state of national electronic prescription systems in the EU in 2018 with special consideration given to interoperability issues. Int J Med Inf 2020;141:104205. https://doi.org/10.1016/j.ijmedinf.2020.104205.

[29.] Wrzosek N, Zimmermann A, Balwicki t. A Survey of Patients' Opinions and Preferences on the Use of E-Prescriptions in Poland. Int J Environ Res Public Health 2021;18:9769. https://doi.org/10.3390/ ijerph18189769.
[30.] Bulgarian National Radio. All prescriptions become electronic on May 1 2021. https://bnr.bg/en/post/101441203/all-prescriptions-become-electronic-on-may-1 (accessed September 27, 2021).

[31.] The Pharmacy Regulator, Medical Council. Guidance for prescribers and pharmacists on legislation changes to facilitate the safe supply of medicines during the COVID-19 pandemic 2020.

[32.] Nehra W. Testing of new e-prescription system begins in Germany. IamExpat 2021. https://www.iamexpat.de/expat-info/german-expat-news/testing-new-e-prescription-system-begins-germany (accessed September 27, 2021).

[33.] Draguet V. Electronic cross-border health services. Public Health - Eur Comm 2019. https:/lec.europa.eu/health/ehealth/electronic crossborder healthservices en (accessed September 27, 2021).

\section{Contact}

Assoc. Prof. Jan Bruthans, M.D., Ph.D.

Všeobecná fakultní nemocnice

U Nemocnice 2, Praha 2, 12000

phone: 723426288

e-mail:jan@bruthans.cz 